\section{Molecular Pathogenesis of Virus Infections}

\author{
Paul Digard, Anthony A. Nash, \\ and Richard E. Randall, editors
}

\section{Cambridge University Press, Cambridge, United Kingdom, 2005 ISBN: 0-52-183248-9}

Pages: 358, Price: US $\$ 125.00$

Molecular Pathogenesis of Virus Infections describes our current understanding of the pathogenesis of selected virus and prion infections. The innate response is an early barrier to virus spread. In this context, $\mathrm{O}$. Haller et al. describe the antiviral activity of type I interferons and the various virus-encoded countermeasures. R.P. van Rij and R. Andino review the role of RNAi as a therapeutic antiviral agent and its use by the host and virus during viral infections. J.L. Whitton gives an overview of the adaptive CD8+ T-cell immune response in the context of virus infections. G. Screaton and J. Mongkolsapaya explain potential roles of Tcell responses in dengue hemorrhagic fever. E. Turnbull and P. Borrow provide a detailed description of the ineffectual roles of the innate and immune responses in the control of HIV and the long road ahead for development of either a prophylactic or therapeutic vaccine.

Transmissible spongiform encephalopathies have perhaps the most unconventional natural history of any infectious agent. J.C. Manson and R.M. Barron describe the diagnosis of transmissible spongiform encephalopathies, the appearance of new strains, and the nature of host susceptibility to disease. C.M. Dixon et al. depict the special problems presented to the host by certain RNA viruses that are maintained and persist in human populations through avoidance or inhibition of apoptosis, innate immune response, and adaptive immune response.

Other viruses infect humans only as incidental hosts and cause epizootics of varying degrees. A.L. Hartman et al. review our current understanding of the pathogenesis of Ebola and Marburg filoviruses, paying particular attention to the factors that contribute to lethal disease. C. Dye and S. Siddell discuss the pathogenesis of feline coronavirus, an animal disease model that has provided insights into the study of the newly recognized disease, severe acute respiratory syndrome. R.G. Webster et al. enumerate the key influenza genes responsible for human pathogenicity, their roles in past pandemics, and the potential of avian influenza virus strains to evolve into highly pathogenic and transmissible viruses for human populations.

Many viruses modify host metabolism and innate/immune responses to their own ends. L. Gray et al. describe the impact of human papillomaviruses on cell cycle and apoptosis. S.M. Lemon and $\mathrm{K}$. Li review the data documenting hepatitis $\mathrm{C}$ virus disruption of innate intracellular antiviral defenses, including interferons and toll-like receptors. M.B. RuizArguello et al. enumerate the multiple, distinct receptor homologs and binding proteins encoded by poxviruses that target tumor necrosis factor. L.K. Dixon summarizes the multiple host pathways that are targeted at multiple levels by African swine fever virus. J.P. Stewart et al. describe the pathogenesis of murid herpesvirus 4 that supports its use as model for gammaherpesviruses. M.L. Freeman et al. provide an overview of the potential role of the immune system in the latency of the alphaherpesvirus, herpes simplex virus 1 . This book is suitable for the serious student and professional and is well referenced for further reading.

\section{Robert Buller*}

*St. Louis University, St. Louis, Missouri, USA

Address for correspondence: Robert Buller, Department of Molecular Microbiology and Immunology, St. Louis University, M432, 1402 South Grand Blvd, St. Louis, MO 63104, USA: fax: 314-977-8717; email: bullerrm@slu.edu

\section{The Germ Freak's Guide to Outwitting Colds and Flu: Guerilla Tactics to Keep Yourself Healthy at Home, at Work, and in the World}

\section{Allison Janse with Charles Gerba}

\section{Health Communications Inc,} Deerfield Beach, FL, 2005

ISBN: 0-7573-0327-7

Pages: 194, Price: US $\$ 9.56$

According to self-described "germ freak" Allison Janse, it's a dangerous world out there and I am not talking about Al Qaeda, anthrax in the mailbox, or Hurricane Katrina. The real danger, according to Janse, comes from elevator buttons (severe acute respiratory syndrome), escalator handrails (group B Streptococcus), subway platforms (Aspergillus) kitchen sinks (salmonella), loofah sponges (Staphylococcus aureus), and children's ball pits (Escherichia coli). She has a point, of course; everyday objects can transmit disease, but the value of her point is frequently lost in a hodgepodge approach that makes no distinction between serious but rare events, everyday avoidable ills, and the merely yucky. 
In this book, Janse and her collaborator Charles Gerba use (sometimes badly misplaced) humor to alert us to the risks we run from everyday items like our kitchen cutting board ("If you have a choice between licking a cutting board or a toilet seat... pick the toilet seat” p. 50). The book does a nice job of addressing the overuse of antimicrobial drugs; encourages even blatant germ freaks to save their money and not buy antimicrobial soap for everyday use; is loaded with useful tips for reducing your family's vulnerability to sharing bugs of all sorts; provides a quick overview of the transmission, symptoms, and incubation period of some of the most common bugs (influenza virus, norovirus, cold viruses, and E. coli); and can induce a mania for handwashing among even the most hygiene-challenged. Unfortunately, the authors spend too much time on items that have no bearing on the transmission of colds and influenza, or anything else for that matter, and not nearly enough time providing detailed, "how-to" instructions.
Even less helpful is an entirely too flippant attitude toward the potentially valuable role that germ freaks can play in public health education. In a section entitled "Operation Germ Evasion," the authors provide a list of suggested responses that germ freaks should memorize, so they won't be caught off guard at a party when faced with ignorant comments from non-germ freaks. Two examples will suffice: 1) Non-germ freak comment, "I read about this hygiene hypothesis that says being too clean is causing increased illness." Suggested response, "I didn't think you knew how to read" (p. 29). 2) Non-germ freak comment, "Children who grow up in homes that are too clean are more likely to have asthma." Suggested response, "Then your kids are safe because your house is a real dump" (p. 29). These responses would not only give Miss Manners serious pause, they overlook a valuable opportunity to teach skills in addressing, and placing in proper context, the kernels of truth embedded in comments such as these. Rather than belit- tling non-germ freaks, the authors would have been better advised to give space to a balanced discussion.

Ultimately, the best audiences for this book are fellow germ freaks, who will enjoy the social validation it provides, and persons with enough preexisting savvy about infectious disease to sort out the helpful tips from the overly dramatic prose ("When you touch the shopping cart handle laden with $E$. coli and then sample the deli turkey, your life could literally be in your own hands" [p. 15]). In context, this book is entertaining and informative, but I would not recommend it for general consumption, without prior sanitization by the informed.

\section{Kimberly Sessions*}

*Emory University, Atlanta, Georgia, USA

Address for correspondence: Kimberly Sessions, Rollins School of Public Health of Emory University, 1518 Clifton Rd NE, Atlanta, GA 30329, USA; fax: 404-727-9853; email: kbs@emory.edu

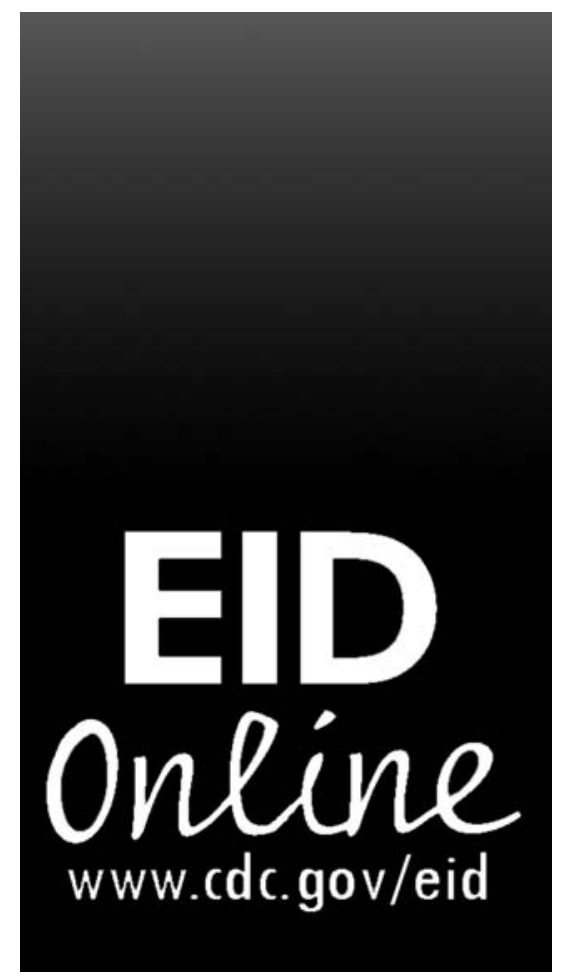

\section{influenza}

$$
\text { [in"floo-en'zə] }
$$

Acute viral infection of the respiratory tract. From Latin influentia, "to flow into"; in medieval times, intangible fluid given off by stars was believed to affect humans. The Italian influenza referred to any disease outbreak thought to be influenced by stars. In 1743, what Italians called an influenza di catarro ("epidemic of catarrh") spread across Europe, and the disease came to be known in English as simply "influenza."

Sources: Dorland's illustrated medical dictionary. 30th ed. Philadelphia: Saunders; 2003 and Quinion M. World wide words. 1998 Jan 3 [cited 2005 Dec 5]. Available from http://www.worldwidewords.org/topicalwords/tw-inf1.htm 